TSG-p53 models-and neonatal mice. For example, Springborn Laboratories (Wareham, MA) and Purdue Pharma (Norwalk, CT) established a joint venture this year to evaluate the TG.AC and TSG-p53 transgenic mouse models using the known rodent carcinogen methapyrilene hydrochloride. Results are due in early 1999.

The setback to transgenic animal models came in March this year. Reports presented at an FDA meeting showed that some TG.AC models-one of several transgenic lines included in the "Oncomouse" patent licensed to Dupont (Wilmington, DE)unexpectedly failed to respond to skin tests.
This slowed progress toward acceptance of transgenic bioassays, according to Stoll, chairman of ILSI's TG.AC Working Group. He says his committee actively disseminated information to scientists about the nonresponder problem and about the need to obtain new TG.AC animals from a purged breeding colony. Taconic Farms (Germantown, NY), the company that produces the TG.AC mouse under contract with the NTP, is now providing animals that are proven to bear the TG.AC responder genotype for identifying carcinogenic agents.

The ILSI committee evaluating the bioassay alternatives had hoped to convene a sym- posium this year to present findings to the FDA and other regulatory agencies, but this is now unlikely to occur before 2000 , says Stoll. However, he says he and some of his colleagues have been impressed with the open-minded attitude of FDA regulatorsthe FDA has reportedly already granted some 20 approvals to use speeded-up transgenic bioassays.

If quicker and cheaper alternatives are proven and accepted, the NTP could expand its public service by greatly increasing the number of compounds it screens annually for cancer risks, without a budget increase.

Neil Swan

\title{
Biotech companies just can't get the staff these days
}

A new company that will supply board members giving strategic and philosophical advice to European bioscience firms was created in London at the start of August. Ziggus Holdings (London) will provide nonexecutive director services to increase the likely success of small and medium-sized biotechnology companies by encouraging the employment of high-level strategic planners as a condition of financial investment.

Ziggus is the brainchild of Geoffrey Vernon, a former executive director of the major UK investment group, Rothschild Bioscience Unit (London). According to Vernon, professional nonexecutives for biotechnology firms that "should help with the strategic planning of a company but not to get involved with the day-to-day operations" are lacking. "It has been proved in the US that the entrepreneur that can take [a product from lab bench to market] is rare," says Vernon.

The idea that it takes more than entrepreneurship to make a company work is now becoming more accepted in Europe. Ruston Poole, a London-based recruitment agency, has been finding nonexecutives for European biotechnology companies for the last five years, including the likes of ex-Genentech CEO Kirk Raab (chair of Oxford GlycoSciences [Oxford, UK]); Morphosys's (Munich, Germany) chair Goran Ando (exvice president worldwide science and technology at Pharmacia \& Upjohn [London]); and nonexecutive director Jürgen Drews (exRoche [Basel, Switzerland] director of global pharmaceutical research). These nonexecutives do not have full-time management roles, but take an overview of the company's philosophy to ensure that on-going operations will take it in the right direction. "The demand is intensifying," says Ruston Poole chair, David Collingham, "at the moment, we are doing about 12 board searches a year, and this is doubling every year."
Vernon intends to offer just this type of board service. However, his strategy differs in that he hopes to work with investment funds. He plans to target venture capital firms and investment banks looking to fund both start-up and later-stage companies. Vernon says that at the point of funding, investment groups often look at the board of a company to assess the additional skills required to ensure the company's success. Vernon plans to offer to fill the gaps in a board's expertise with his own skills and experience, presenting himself to the company via the investor. Ultimately, the company may not receive funding unless it agrees to take the advice of the investor and employ nonexecutive services such as those offered by Vernon.

"What I'm offering is a plethora of skills," says Vernon. These, he believes, allow him to have an overview of what will happen to a company as it develops and how to prepare for maximum benefit. "A changing skills base is required to take a company from 10 to 100 people. [This involves] preparing the board and positioning the company for the strategies needed to develop," says Vernon.

Even European start-ups with links to established US companies are having difficulty finding nonexecutives with the experience and management skills necessary to take a product from initiation to market. Atugen (Berlin) - the newly formed collaboration between Ribozyme Pharmaceutical (Boulder, CO) and Transgenics (Berlin) (Nat. Biotechnol. 16:812, 1998)-is currently recruiting but so far haven't found anyone with the right credentials and experience. "We want the top candidates, but it is very difficult to recruit," says Jorg Poetzsch, vice president for administration and finance at Atugen. "For smaller start-up companies [recruitment services] could be [most] use- ful," says Claus Kremoser, director of strategy and business development for Lion Biosciences (Heidelberg, German), a leading German biotechnology firm specializing in genomic sequencing and bioinformatics.

EuropaBio, the trade association for European biotechnology firms, agrees. "Start-up companies direct from university will be profiting the most from [nonexecutives]," says Anthony Aarke, EuropaBio executive director, explaining that scientists who set up new firms rarely have business or management skills. The combination of science with management "would help in the development of proper companies," he says.

Unfortunately, Kremoser thinks that start-ups will not make use of recruitment agencies to find management skills. Small companies "don't have the idea of using executives as they think they can do it on their own," he says, adding that the cost may also be a deterrent. He doesn't see this type of recruitment service having a significant impact immediately but adds, "it may well increase in the future."

Spin-outs from universities and other early-stage companies are not the whole picture, according to Collingham and Vernon. They both cite the recent senior management departures from British Biotech (Oxford, UK) (Nat. Biotechnol. 16:609, 1998) as indicative of poor communication and lack of long-term vision among the senior management of Europe's largest biotechnology company. "The recent blowup in the UK market has highlighted the ongoing need for professional nonexecutives [for all biotechnology firms]," says Vernon, pointing out that larger public companies require strategic planning as much as smaller ones. "Once a company has gone public, it still needs to adapt and changeremember the dinosaur."

Adam Michael 